\title{
Metabolomics reveal that octocrylene accumulates in Pocillopora damicornis tissues as fatty acid conjugates and triggers coral cell mi- tochondrial dysfunction
}

\author{
Didier Stien $^{\dagger}, *$, Fanny Clergeaud ${ }^{\dagger}$, Alice M. S. Rodrigues ${ }^{\dagger}$, Karine Lebaron ${ }^{\dagger}$, Rémi Pillot ${ }^{\ddagger}$, Pascal Ro- \\ mans $^{\ddagger}$, Sonja Fagervold ${ }^{\dagger}$, Philippe Lebaron ${ }^{\dagger, *}$ \\ ${ }^{\dagger}$ Sorbonne Université, CNRS, Laboratoire de Biodiversité et Biotechnologie Microbienne, LBBM, Observatoire Océanolo- \\ gique, 66650 Banyuls-sur-mer, France \\ ¥ Sorbonne Université, CNRS, Fédération de Recherche, Observatoire Océanologique, 66650 Banyuls-sur-mer, France.
}

\begin{abstract}
Octocrylene (OC) is an ingredient used in many sunscreens and cosmetics worldwide. Our group evaluated the toxicity of OC in corals. Adult Pocillopora damicornis coral was treated with OC at concentrations of 5, 50, 300 and $1000 \mu \mathrm{g} / \mathrm{L}$. Most polyps were closed at concentrations of $300 \mu \mathrm{g} / \mathrm{L}$ and higher. Further, metabolomic profiling provided crucial information regarding OC accumulation in coral tissues and OC toxicity. First, we demonstrated that OC was transformed into fatty acid conjugates via oxidation of the ethylhexyl chain, yielding very lipophilic OC analogs that accumulate in coral tissues. Second, the differential analysis of coral profiles revealed higher levels of 15 acylcarnitines, suggesting abnormal fatty-acid metabolism related to mitochondrial dysfunction. The formation of OC analogs suggests that OC concentrations measured in the environment and organisms may have been largely underestimated. Overall, these results call for an in-depth evaluation of OC toxicity and the reevaluation of the actual OC accumulation rate in the ocean's food chain, including OC-fatty acid conjugates.
\end{abstract}

The use of sunscreens is crucial for global cancer prevention. ${ }^{1}$ However, environmental concerns have arisen, as some active ingredients are considered harmful to humans and wildlife, including corals, therefore contributing to global coral reef decline, with 14,000 tons of sunscreen ending up in oceans every year. ${ }^{2-6}$ Recently, in an effort to protect coral reefs, Hawaii was the first state in the USA to ban sunscreens that contain oxybenzone and octinoxate. This law should come into effect in January 2021.

Octocrylene (OC, CAS No. 6197-30-4, Figure 1) is an ingredient used in many sunscreens and also in other cosmetics such as hair sprays, tannin oils, blemish balm creams, and conditioners. Hence, $\mathrm{OC}$ is continuously released into marine and freshwater environments from wastewater treatment plants and through more direct sources, namely, people bathing in these environments. OC should therefore be considered a pseudo-persistent pollutant. Indeed, OC is among the most frequently detected solar filters in the environment, with concentrations of up to $7 \mu \mathrm{g} / \mathrm{L}$ and high seasonal variations. ${ }^{7,8} \mathrm{OC}$ is lipophilic, with a Log P of 6.88. ${ }^{9}$ Thus, OC tends to accumulate in sediments where higher concentrations are found. ${ }^{10}$ ${ }^{15} \mathrm{OC}$ also concentrates in the lipophilic tissues of aquatic organisms at various trophic levels, ranging from filtering organisms, such as mussels, to dolphins. ${ }^{16-23}$ As a consequence, the actual water column concentration may not reflect the concentration at which marine organisms are actually exposed.

In a preliminary assay with a concentration of $1 \mathrm{mg} / \mathrm{L}, \mathrm{OC}$ showed potential toxicity towards the coral reef builder species Pocillopora damicornis. Polyps were consistently closed during exposure. However, a concentration of $1 \mathrm{mg} / \mathrm{L}$ is much higher than any environmental concentration measured for this compound, and we aimed to examine the effects of $\mathrm{OC}$ at concentrations ranging from 5 to $1000 \mu \mathrm{g} / \mathrm{L}$.<smiles>CCC(CC)COC(=O)C(C#N)=C(c1ccccc1)c1ccccc1</smiles>

Figure 1. Chemical structure of octocrylene (OC)

\section{EXPERIMENTAL SECTION}

Pocillopora damicornis. Samples of the coral P. damicornis were collected in Oman and were acclimated for more than 1 year in tanks at the Banyuls Oceanological Observatory. Corals were maintained in artificial sea water (ASW) prepared with reverse osmosis-purified water and Reef Salt ${ }^{\mathrm{TM}}$ SeaChem salts. Salinity was adjusted to $36 \mathrm{~g} / \mathrm{L}, \mathrm{pH}=8$, and the temperature was set at $24{ }^{\circ} \mathrm{C}$. All experiments were conducted with the same ASW.

Preparation of coral for exposition to solar filters. Coral pieces $(1-1.5 \mathrm{~cm})$ were cut from branch tips from the same mother colony. Each piece was attached to a fishing line, and the coral pieces were then suspended three by three on an $\sim 5$ $6 \mathrm{~cm}$ laminated iron wire, making sure the lines had the appropriate length so that the coral pieces did not touch the beaker edge or bottom during the assay. Each suspension of 3 coral pieces ( 3 replicates) was clamped to a line above the aquarium of origin, thereby immerging the pieces. The suspended pieces were acclimatized for approximately 1 month before the assay to allow for full healing. 
Exposure setup. Beakers $(250 \mathrm{~mL})$ were filled with ASW (200 mL). OC ( $\geq 98.0 \%$, Sigma-Aldrich) was dissolved in DMSO at concentrations of 400, 120, 20 and $2 \mu \mathrm{g} / \mathrm{mL}$. Each of these solutions $(500 \mu \mathrm{l})$ was added into separate beakers, resulting in final concentrations of $1000,300,50$, and $5 \mu \mathrm{g} / \mathrm{L}$. DMSO $(500 \mu \mathrm{L})$ was used as a negative control, and the DMSO concentration was $0.25 \% \mathrm{v} / \mathrm{v}$ in all beakers. The suspensions of 3 coral pieces were dipped into the beakers, with the wire positioning the pieces halfway into the water. Gentle bubbling in the beakers was maintained using aquarium air pumps equipped with a Teflon tubing. Homogeneous lighting was set to a photosynthetic photon flux density of 250 $\mu \mathrm{mol} / \mathrm{m}^{2} / \mathrm{s}$, with $10 \mathrm{~h}$ of day and $14 \mathrm{~h}$ of night per day. The corals were transferred every $24 \mathrm{~h}$ to a new beaker prepared in the same way. The total exposure lasted for 7 days. Pictures were taken every $24 \mathrm{~h}$ to monitor coral polyps. Coral exposure at $1000 \mu \mathrm{g} / \mathrm{L}$ OC was repeated in a separate experiment to confirm the result.

Extraction. After 7 days, the coral pieces were collected, and the fishing lines were removed with a scalpel. Each coral piece was placed into a $20-\mathrm{mL}$ test tube, covered with $\mathrm{MeOH} /$ acetonitrile $1 / 1$, and sonicated for $20 \mathrm{~min}$. Once the polyps were dissolved, the solvent was filtered through a 6mL/1-g C-18 SPE cartridge previously equilibrated with $\mathrm{MeOH}$. The solid phase was rinsed with $\mathrm{MeOH}(1 \mathrm{~mL})$, and the eluates were evaporated and kept at $-80{ }^{\circ} \mathrm{C}$ until analysis. All solvents used for extraction and profiling were LC-MS gradient grade (Biosolve, Dieuze, France).

UHPLC-HRMS profiling. High-resolution MS/MS analyses were conducted with a Thermo UHPLC-HRMS system. Analyses were performed in the electrospray positive ionization mode in the range of 133.4-2000 Da in centroid mode. The mass detector was an Orbitrap MS/MS FT Q-Exactive focus mass spectrometer. The analyses were conducted in FullMS data dependent $\mathrm{MS}^{2}$ mode. In FullMS, the resolution was set to 70,000, and the AGC target was $3.10^{6}$. In $\mathrm{MS}^{2}$, the resolution was 17,500 , AGC target $10^{5}$, isolation window 0.4 $\mathrm{Da}$, and stepped normalized collision energy 15/30/45 was used, with $15 \mathrm{~s}$ dynamic exclusion. The lock mass option was set for ion at $\mathrm{m} / \mathrm{z} 144.98215$, corresponding to $\mathrm{Cu}\left(\mathrm{CH}_{3} \mathrm{CN}\right)_{2}{ }^{+}$. The UHPLC column was a Phenomenex Luna Omega polar $\mathrm{C}-18150 \times 2.1 \mathrm{~mm}, 1.6 \mu \mathrm{m}$. The column temperature was set to $42{ }^{\circ} \mathrm{C}$, and the flow rate was $0.5 \mathrm{~mL} \cdot \mathrm{min}^{-1}$. The solvent system was a mixture of water (solution A) with increasing proportions of acetonitrile (solution B), both solvents modified with $0.1 \%$ formic acid. The gradient was as follows: $2 \%$ B 3 min before injection, then from 1 to $13 \mathrm{~min}$, a shark fin gradient increase of B up to $100 \%$ (curve 2), followed by $100 \%$ B for $5 \mathrm{~min}$. The flow was diverted (not injected into the mass spectrometer) before injection, up to $1 \mathrm{~min}$ after injection.

The coral extracts were dissolved in $\mathrm{MeOH}(1 \mathrm{mg} / \mathrm{mL})$ by sonication, and $2 \mu \mathrm{L}$ was injected onto the column. Standard of 2-ethyl-5-hydroxyhexyl 2-cyano-3,3-diphenyl acrylate (5$\mathrm{OH}-\mathrm{OC}) 1$ in acetonitrile $(1 \mu \mathrm{g} / \mathrm{mL}, 1 \mu \mathrm{L}$ injected) was provided by Prof. Daniel Bury (Ruhr-Universität Bochum). Standard of acylcarnitines 20-24, 26, 28, and 30 were acquired from AnalyticLab, Montpellier, France (Table S2). A mixture of acylcarnitines $(\approx 5 \mu \mathrm{g} / \mathrm{mL}$ each) in $\mathrm{MeOH}$ was injected (1 $\mu \mathrm{L})$ in the same conditions for comparison of retention times, MS and MS/MS spectra. All standards were identical to the coral acylcarnitines based on comparison of retention time, MS and MS/MS spectra.
Metabolomic analyses. Profiles were analyzed with Compound Discoverer ${ }^{\circledR}$ (CD) 2.1 (ThermoFisher, Villebon, France). Coral exposed to DMSO was used as the reference metabolome, and blank injections were used to remove irrelevant ion peaks (ion peak is considered only if the signal is at least 5 times more intense than in the blank). An untargeted metabolomic workflow was used, with modifications. This workflow finds and identifies the differences between samples, and performs retention time alignment, unknown compound detection, and compound grouping across all samples. The workflow predicts elemental compositions for all compounds, fills gaps across all samples, hides chemical background (using Blank samples); identifies compounds using mzCloud (ddMS2) and ChemSpider (formula or exact mass); performs similarity searches for all compounds with ddMS2 data using mzCloud; maps compounds to biological pathways using KEGG database; and calculates a differential analysis ( $t$ test or ANOVA) and determines $p$-values, adjusted $p$-values, ratios, fold change.

The retention time window was set to $2-17 \mathrm{~min}$. The maximum shift for alignment was $0.1 \mathrm{~min}$, the maximum mass tolerance was $3 \mathrm{ppm}$, and the minimum peak intensity was $2.10^{6}$. Statistical analyses (Principal Component Analysis [PCA], volcano plots) were performed with CD using centered and scaled data.

\section{RESULTS AND DISCUSSION}

Small, suspended coral pieces were treated for 7 days with OC at concentrations of 5, 50, 300 and $1000 \mu \mathrm{g} / \mathrm{L}$. The water was changed every $24 \mathrm{~h}$. At the end of each exposure, pictures were taken to observe potential macroscopic differences. At concentrations of $300 \mu \mathrm{g} / \mathrm{L}$ and higher, most polyps were closed (see supporting information, Figure S111). Thus, coral polyps appeared to be impacted at these concentrations. The extracts prepared from the coral pieces were analyzed by UHPLC-ESI ${ }^{+}-\mathrm{HRMS}^{2}$. The metabolomic profiles were compared with those of control corals treated with DMSO only.

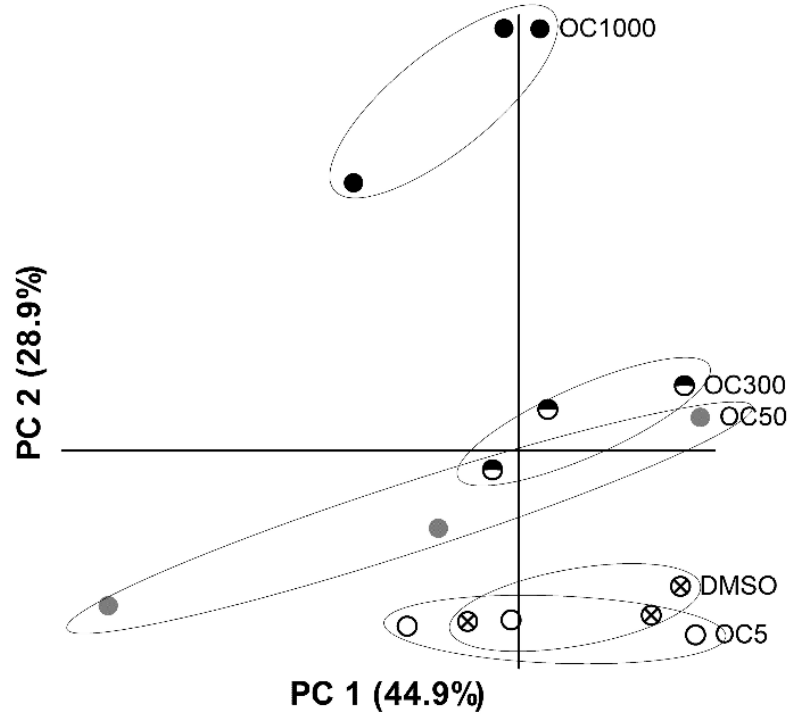

Figure 2. PCA comparing metabolomic profiles of coral treated at different concentrations of OC. OC concentrations are reported on the graph, in $\mu \mathrm{g} / \mathrm{L}$. DMSO stands for the control sample. 

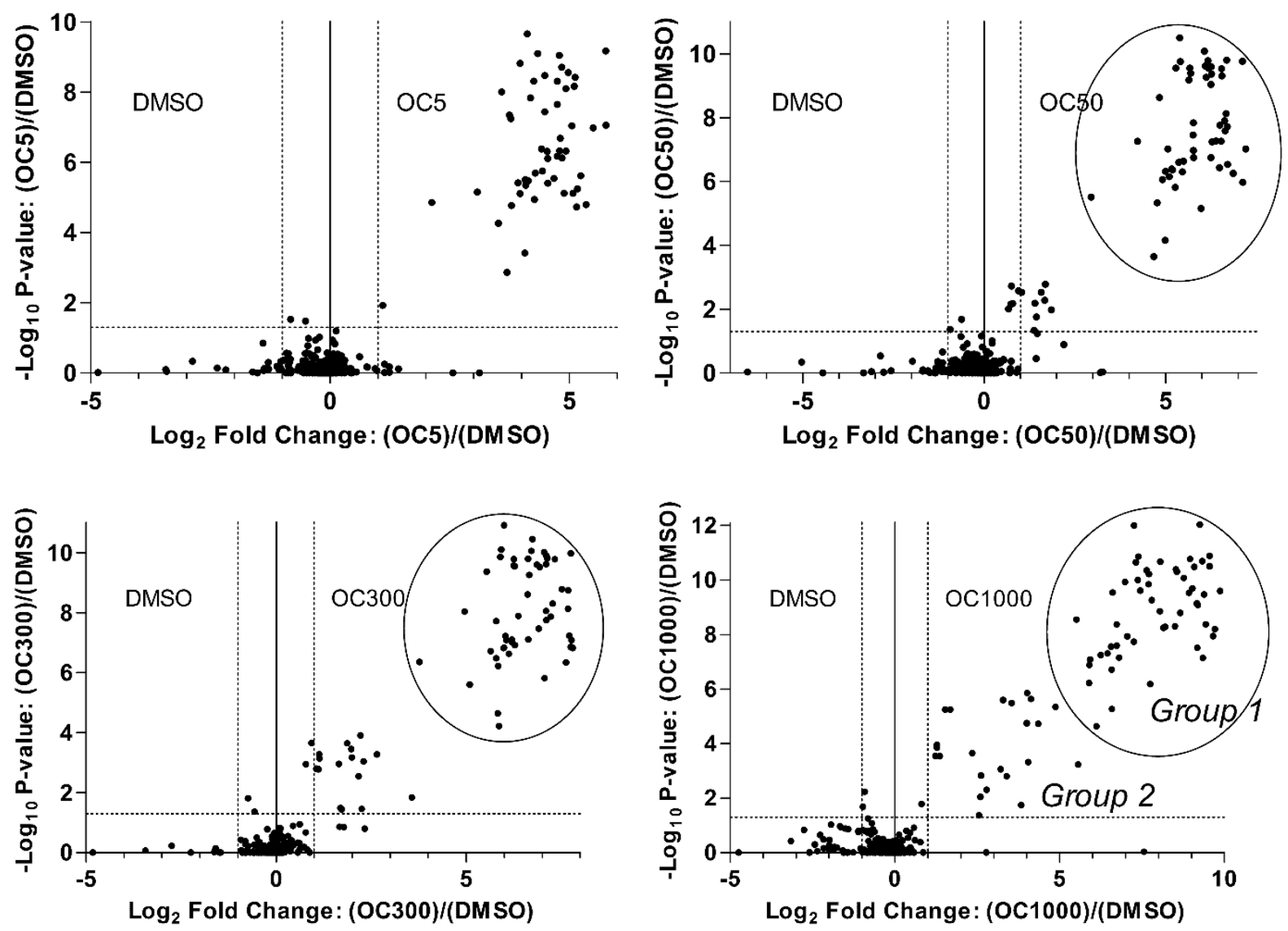

Figure 3. Volcano plots comparing OC treatments with DMSO. The horizontal dashed line indicates a $p$ value of 0.05 : all ions above this line are significantly up-regulated in one condition compared to the other. Vertical dashed lines indicate Log 2 fold changes of -1 and +1 . One group of ions is up-regulated in all OC treatments, even at $5 \mu \mathrm{g} / \mathrm{L}$ (group 1). This group of ions has been circled in the volcano plots from 50 to $1000 \mu \mathrm{g} / \mathrm{L} \mathrm{OC}$.

After extraction of the ion chromatograms with Compound Discoverer software, profiles were first compared using a PCA (Figure 2). Principal components 1 and 2 described up to 73.8 $\%$ of the variability in the dataset. Interestingly, while the observations seemed to be distributed along the PC1 axis, there was a clear OC dose-effect observed along the PC2 axis. OC-treated corals were different from the controls at concentrations of $50 \mu \mathrm{g} / \mathrm{L} \mathrm{OC}$ and higher. The metabolites that changed significantly between the different conditions can be viewed with volcano plots (Figure 3 ). The volcano plots indicated two groups of ions. Ions from group 1 (circled in Figure 3 ) were present in the samples treated with all concentrations of OC, while ions from group 2 (not circled) were progressively moving into the zone of statistical significance as OC concentration increased.

In group 1, 53 ions accounting for 20 molecules were significantly more abundant in all samples treated with OC, even at $5 \mu \mathrm{g} / \mathrm{L}$. OC was among the 20 compounds, at $t_{R} 9.60 \mathrm{~min}$ and $m / z 250.0863\left([\mathrm{M}+\mathrm{H}]^{+}\right)$. Compound 3, one of the major compounds among the remaining 19, was represented by 9 ions at $\mathrm{t}_{\mathrm{R}} 15.64 \mathrm{~min}(\mathrm{~m} / \mathrm{z}, 232.0758$ [fragment], 250.0863 [fragment], $359.18862 \quad\left[\right.$ fragment], $616.4368 \quad[\mathrm{M}+\mathrm{H}]^{+}, \quad 633.4633$ $\left[\mathrm{M}+\mathrm{NH}_{4}\right]^{+}, 638.4181[\mathrm{M}+\mathrm{Na}]^{+}, 654.3918[\mathrm{M}+\mathrm{K}]^{+}, 661.4934$ $\left[\mathrm{M}+\mathrm{C}_{2} \mathrm{H}_{7} \mathrm{~N}+\mathrm{H}\right]^{+}$, and 703.5044 [unidentified]) (see Support- ing Information). The pseudomolecular ion was identified by $\mathrm{CD}$ as 'Similar to: 2-Cyano-3,3-diphenylacrylic acid ethyl ester; $\Delta$ Mass: -338.3188 Da'. Since OC is 2-cyano-3,3diphenylacrylic acid 2-ethylhexyl ester, we suggested that compound 3 could be a higher molecular weight analog of OC, presumably a biotransformation product. The compound 3 pseudomolecular ion had the molecular formula $\mathrm{C}_{40} \mathrm{H}_{58} \mathrm{NO}_{4}$, as deduced from the ion at $\mathrm{m} / z, 616.4368$ (calcd. 616.4360), requiring 13 degrees of unsaturation. $\mathrm{OC}$ had 12 unsaturations and the molecular formula $\mathrm{C}_{24} \mathrm{H}_{27} \mathrm{NO}_{2}$. The difference between the two molecules indicates that a $\mathrm{C}_{16} \mathrm{H}_{30} \mathrm{O}_{2}$ moiety has been added to OC, i.e., a C16:0 lipid chain, most likely a palmitic acid group.

Key pieces of information were found in the MS/MS spectrum of the pseudomolecular ion of compound $\mathbf{3}$ (Figure 4). First, the peaks at $m / z, 250.0863,232.0757$ and 204.0808 were also found in the OC MS/MS spectrum. These peaks correspond to the successive loss of the 2-ethylhexyl chain, $\mathrm{H}_{2} \mathrm{O}$, and CO. These 3 fragments demonstrate that $\mathbf{3}$ is indeed an octocrylene analog and that the modification did not occur on the carboxylic acid part of the molecule. Second, the fragment ion at $\mathrm{m} / \mathrm{z} 360.1958$ corresponds to the $\beta$-elimination of a C16:0 fatty acid. Altogether, these data show that compound 3 is an OC derivative, modified on the 2-ethylhexyl chain by 
oxidation and esterification with a C16:0 fatty acid (Figure 5). The oxidation site cannot be determined by MS. In addition, compound $\mathbf{4}$ is in fact an isomer of compound $\mathbf{3}$, suggesting that the 2-ethylhexyl chain may be oxidized in different positions. The pseudomolecular ion is relatively small and was not always selected by the spectrometer for fragmentation. In this case, the MS/MS spectrum of the $\left(\mathrm{M}+\mathrm{NH}_{4}\right)^{+}$adduct was used. This ion loses ammonia and eventually yields the same fragments as the pseudomolecular ion. In the MS/MS spectrum of the sodium adduct, the diagnostic fragment ions were at $\mathrm{m} / \mathrm{z}$ $382.1778\left(\mathrm{C}_{24} \mathrm{H}_{25} \mathrm{NO}_{2} \mathrm{Na}^{+}\right)$and $272.0682\left(\mathrm{C}_{16} \mathrm{H}_{11} \mathrm{NO}_{2} \mathrm{Na}^{+}\right)$. We were able to demonstrate that all biomarkers from group 1 were OC bioconversion products, resulting from oxidation of the side chain and subsequent esterification with C14 to C22 fatty acids.

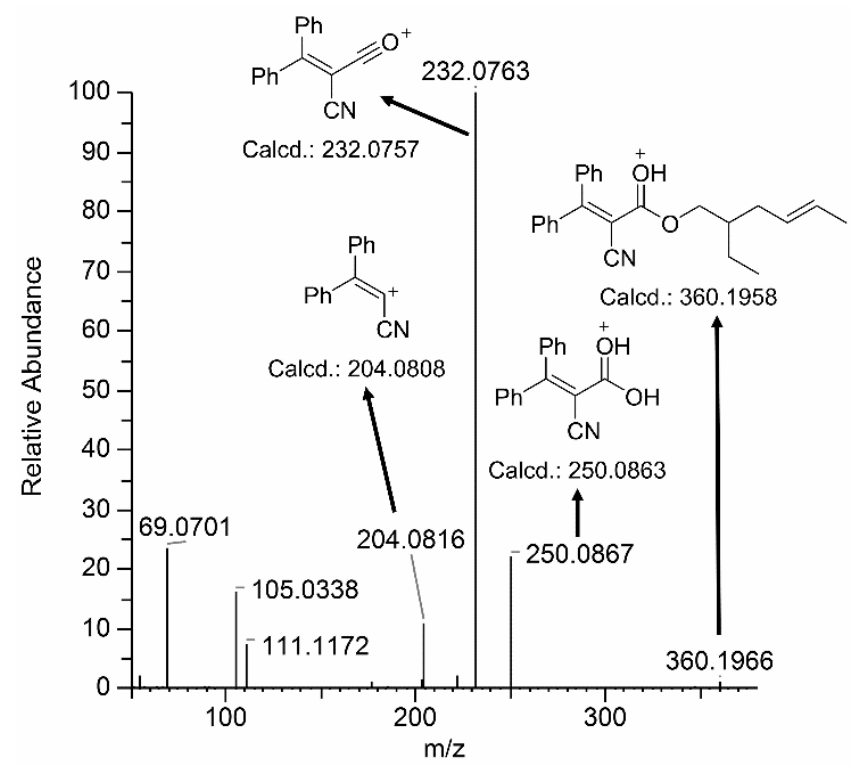

Figure 4. MS/MS spectrum of the compound 3 pseudomolecular ion and identification of the key fragment ions.

Compound 1 was identical to a standard of 5-hydroxy-OC recently detected in human urine, ${ }^{24}$ suggesting that the same biotransformation pathways may occur in human. Compounds 5 and 6 were oxidized twice on the ethylhexyl side chain, as demonstrated by the double elimination fragment at $\mathrm{m} / \mathrm{z}$ 358.1802 in the MS/MS spectrum of the $(5+\mathrm{NH} 4)^{+}$parent ion and the corresponding monohydrate at $\mathrm{m} / \mathrm{z} 398.1719$ in the MS/MS spectrum of the $(6+\mathrm{Na})^{+}$ion. Overall, oxidation always occurred on the 2-ethylhexyl chain. All analytical data are provided in the supporting information.

It is unclear why the coral or any associated living organism would be coupling fatty acids to OC. Nevertheless, this process makes OC more lipophilic, presumably resulting in its accumulation in coral tissues. OC itself has been found to accumulate in the food chain, from shells to marine mammals. ${ }^{16,21}$ Based on our findings, it is likely that the accumulation rate may have been largely underestimated and that OCfatty acid conjugates may in fact be present in much higher overall amounts in the same tissues.

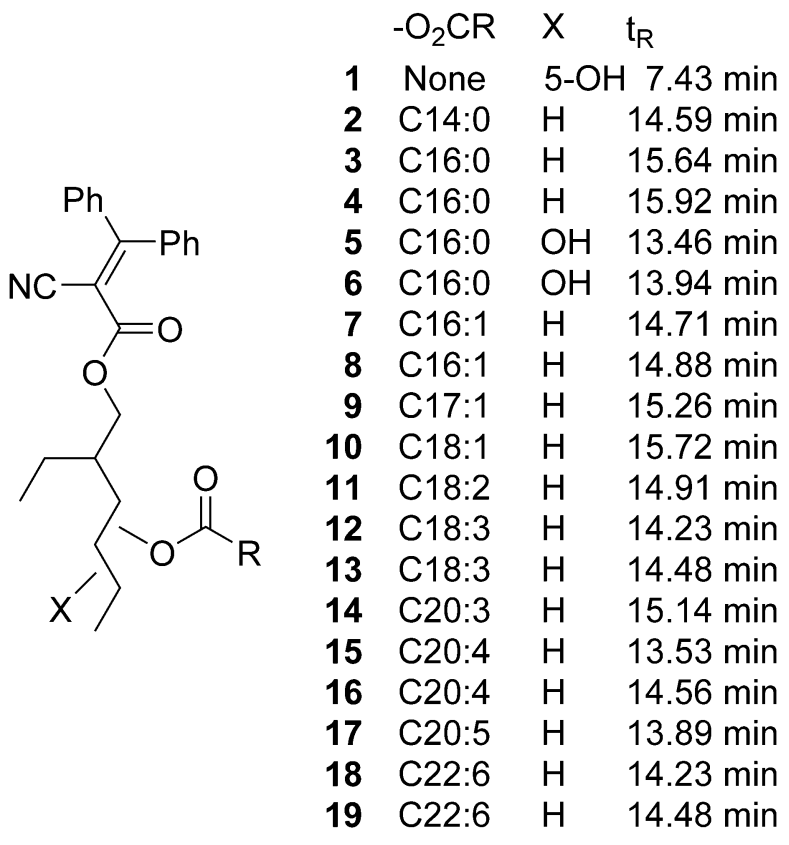

Figure 5. Group 1 biomarkers with their respective retention times.

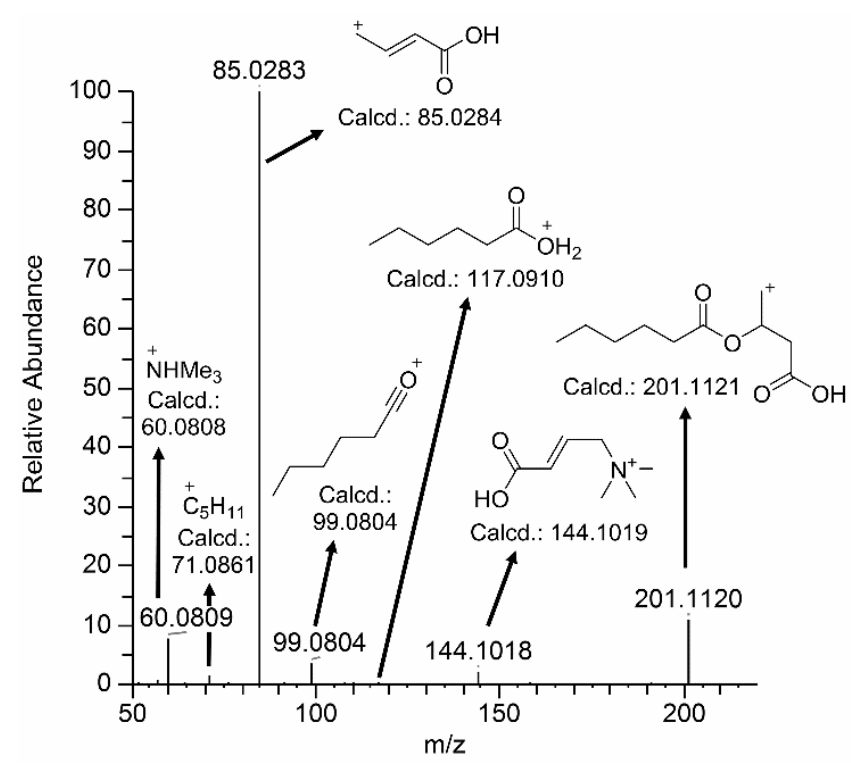

Figure 6. MS/MS spectrum of the compound 21 pseudomolecular ion and identification of the key fragment ions.

The second group of biomarkers includes 23 ions in the samples treated with $1000 \mu \mathrm{g} / \mathrm{L}$ OC, corresponding to 20 compounds numbered from $\mathbf{2 0}$ to 38 . Compound Discoverer identified many of these ions as acylcarnitines. For example, compound $\mathbf{2 1}$ at $t_{R} 4.78 \mathrm{~min}$ was identified as hexanoylcarnitine. This compound was identified in the MS data by its pseudomolecular ion at $\mathrm{m} / \mathrm{z} 260.1857$ corresponding to the molecular formula $\mathrm{C}_{13} \mathrm{H}_{26} \mathrm{NO}_{4}\left([\mathrm{M}+\mathrm{H}]^{+}\right.$, calcd. 260.1856), requiring 2 degrees of unsaturation. In the MS/MS spectrum (Figure 6), the 3 fragment ions at $m / z, 144.1019,85.0284$ and 60.0808 were attributed to the carnitine moiety and were found in compounds $\mathbf{2 0 - 3 5}$, thereby confirming that all these 
metabolites were acylcarnitines. The fragment ions at $\mathrm{m} / \mathrm{z}$ 117.0910, 99.0804 and 71.0861 were specific to the hexanoyl chain and further demonstrated that compound $\mathbf{2 1}$ is hexanoylcarnitine (Figure 7).

Identification of compounds 20-35 was achieved following the same rationale as above. In addition, comparison of the analytical data from compounds 20-24, 26, 28, and 30 to those of commercially available standards confirmed their identification. All data are provided in the supporting information.

In group 2, 3 ions corresponding to 3 different molecules were not attributable to acylcarnitines and could not be identified (compounds 36-38, Figure 7). Based on their molecular formula and fragmentation patterns, compounds $\mathbf{3 6}$ and 37 may be ceramides, although further evidence is needed to provide accurate identification.

\begin{tabular}{|c|c|c|c|}
\hline & & $-\mathrm{O}_{2} \mathrm{CR}$ & $t_{R}$ \\
\hline & 20 & C4:0 & $4.02 \mathrm{~min}$ \\
\hline & 21 & C6:0 & $4.78 \mathrm{~min}$ \\
\hline & 22 & C8:0 & $5.19 \mathrm{~min}$ \\
\hline & 23 & C10:0 & $5.57 \mathrm{~min}$ \\
\hline & 24 & C12:0 & $5.98 \mathrm{~min}$ \\
\hline & 25 & C12:1 & $5.77 \mathrm{~min}$ \\
\hline & 26 & C14:0 & $6.43 \mathrm{~min}$ \\
\hline 0 & 27 & C14:1 & $6.19 \mathrm{~min}$ \\
\hline$=0$ & 28 & C14:2 & $5.96 \mathrm{~min}$ \\
\hline U & 29 & C14:3 & $5.76 \mathrm{~min}$ \\
\hline Acylcarnitines & 30 & C16:0 & $6.94 \mathrm{~min}$ \\
\hline & 31 & C16:1 & $6.57 \mathrm{~min}$ \\
\hline & 32 & C16:1 & $6.69 \mathrm{~min}$ \\
\hline & 33 & C18:1 & $7.09 \mathrm{~min}$ \\
\hline & 34 & C18:3 & $6.53 \mathrm{~min}$ \\
\hline & 35 & C21:5 & $6.51 \mathrm{~min}$ \\
\hline
\end{tabular}

Figure 7. Group 2 biomarkers with their respective retention times.

The relative peak areas for compounds 20-38 compared to the control sample with DMSO are provided in supporting information (Figure S3). The graph indicates that the proportions of most biomarkers were higher in the samples treated with $50 \mu \mathrm{g} / \mathrm{L} \mathrm{OC}$ and higher, although all these compounds were also detected in the samples not exposed to OC. Relative concentrations of the acylcarnitines increased as much as 40 times at the highest OC concentration. Clearly, OC alters coral metabolism at $50 \mu \mathrm{g} / \mathrm{L}$, with a safe concentration of $5 \mu \mathrm{g} / \mathrm{L}$. However, it is worth mentioning that our assay only lasted 1 week, while coral are exposed for much longer periods in the natural environment. Owing to the accumulation potential of OC and OC-fatty acid conjugates, which were readily detected in samples treated with $5 \mu \mathrm{g} / \mathrm{L}$, it can be predicted that $\mathrm{OC}$ may alter coral metabolism at lower concentrations following prolonged exposure.
The elevation of acylcarnitines in the treated coral suggests that there may be abnormalities in fatty-acid metabolism. Acylcarnitines are common biomarkers of cell toxicity, and, in many models including human pathologies, elevated acylcarnitine concentration has been correlated with mitochondrial dysfunction in which mitochondrial fatty acid $\beta$-oxidation and cell bioenergetics are affected..$^{25-28}$

\section{CONCLUSION}

In conclusion, we demonstrated that the coral reef builder species $P$. damicornis is significantly impacted by $\mathrm{OC}$ after only 7 days of exposure to $50 \mu \mathrm{g} / \mathrm{L} \mathrm{OC}$. The highest non-toxic OC concentration in our assay was $5 \mu \mathrm{g} / \mathrm{L}$. This concentration is within the same order of magnitude as water column concentrations measured in several locations. Nevertheless, corals are subjected to long-term exposure (from several weeks and months per year) at high OC concentrations due to a continuous release of OC into the environment. The propensity of OC to accumulate in living organisms, including filtering species (mussels, oysters, etc.) and coral ${ }^{23}$ may increase the concentration at which marine organisms are actually exposed. The discovery of lipophilic OC metabolites calls for the reevaluation of the actual accumulation rate in the ocean food chain. Future titrations should include OC fatty acid conjugates to measure the total amount of OC that is effectively present at each of the different trophic levels in the marine ecosystems.

\section{ASSOCIATED CONTENT}

\section{Supporting Information}

The Supporting Information is available free of charge on the ACS Publications website.

Supporting information includes detailed data for octocrylene and compounds 1-38, including FullMS and MS/MS spectra for each and fragmentation schemes. It also includes extracted ion chromatograms of metabolomic profiles compared with chromatograms of standards, a figure reporting the relative peak areas of group 2 biomarkers between OC-treated corals and control ones, and an image of corals after 7 days of exposition to OC at all concentrations tested.

\section{AUTHOR INFORMATION}

\section{Corresponding Authors}

* E-mail: didier.stien@cnrs.fr

* E-mail: philippe.lebaron@obs-banyuls.fr

\section{Author Contributions}

The manuscript was written through contributions of all authors. All authors have given approval to the final version of the manuscript.

\section{ACKNOWLEDGMENT}

We thank the BIO2MAR platform (http://bio2mar.obs-banyuls.fr) for providing technical support and access to instrumentation. The authors would like to express their appreciation to Prof. Daniel Bury (Ruhr-Universität Bochum) who kindly provided an analytical standard of 5-OH-OC (3).

\section{REFERENCES}


(1) Azoury, S. C.; Lange, J. R. Epidemiology, risk factors, prevention, and early detection of melanoma. Surg. Clin. North Am. 2014, 94, 945-962.

(2) Downs, C. A.; Kramarsky-Winter, E.; Fauth, J. E.; Segal, R.; Bronstein, O.; Jeger, R.; Lichtenfeld, Y.; Woodley, C. M.; Pennington, P.; Kushmaro, A.; Loya, Y. Toxicological effects of the sunscreen UV filter, benzophenone-2, on planulae and in vitro cells of the coral, Stylophora pistillata. Ecotoxicology 2014, 23 , 175-191.

(3) Downs, C. A.; Kramarsky-Winter, E.; Segal, R.; Fauth, J.; Knutson, S.; Bronstein, O.; Ciner, F. R.; Jeger, R.; Lichtenfeld, Y.; Woodley, C. M.; Pennington, P.; Cadenas, K.; Kushmaro, A.; Loya, Y. Toxicopathological effects of the sunscreen UV filter, oxybenzone (benzophenone-3), on coral planulae and cultured primary cells and its environmental contamination in Hawaii and the U.S. Virgin Islands. Arch. Environ. Contam. Toxicol. 2015, 70, 265-288.

(4) Molins-Delgado, D.; Olmo-Campos, M. del M.; Valeta-Juan, G.; Pleguezuelos-Hernández, V.; Barceló, D.; Díaz-Cruz, M. S. Determination of UV filters in human breast milk using turbulent flow chromatography and babies' daily intake estimation. Environ. Res. 2018, 161, 532-539.

(5) DiNardo, J. C.; Downs, C. A. Dermatological and environmental toxicological impact of the sunscreen ingredient oxybenzone/benzophenone-3. J. Cosmet. Dermatol. 2018, 17, 15-19.

(6) Lu, S.; Long, F.; Lu, P.; Lei, B.; Jiang, Z.; Liu, G.; Zhang, J.; Ma, S.; Yu, Y. Benzophenone-UV filters in personal care products and urine of schoolchildren from Shenzhen, China: Exposure assessment and possible source. Sci. Total Environ. 2018, 640-641, 12141220 .

(7) Tsui, M. M. P.; Leung, H. W.; Wai, T.-C.; Yamashita, N.; Taniyasu, S.; Liu, W.; Lam, P. K. S.; Murphy, M. B. Occurrence, distribution and ecological risk assessment of multiple classes of UV filters in surface waters from different countries. Water Res. 2014, 67, 55-65.

(8) Langford, K. H.; Thomas, K. V. Inputs of chemicals from recreational activities into the Norwegian coastal zone. J. Environ. Monit. 2008, 10, 894-898.

(9) Meylan, W. M.; Howard, P. H. Atom/fragment contribution method for estimating octanol-water partition coefficients. J. Pharm. Sci. 1995, 84, 83-92.

(10) Amine, H.; Gomez, E.; Halwani, J.; Casellas, C.; Fenet, H. UV filters, ethylhexyl methoxycinnamate, octocrylene and ethylhexyl dimethyl PABA from untreated wastewater in sediment from eastern Mediterranean river transition and coastal zones. Mar. Pollut. Bull. 2012, 64, 2435-2442.

(11) Kameda, Y.; Kimura, K.; Miyazaki, M. Occurrence and profiles of organic sun-blocking agents in surface waters and sediments in Japanese rivers and lakes. Environ. Pollut. 2011, 159, 1570-1576.

(12) Kaiser, D.; Wappelhorst, O.; Oetken, M.; Oehlmann, J. Occurrence of widely used organic UV filters in lake and river sediments. Environ. Chem. 2012, 9, 139-147.

(13) Rodil, R.; Moeder, M. Development of a simultaneous pressurised-liquid extraction and clean-up procedure for the determination of UV filters in sediments. Anal. Chim. Acta 2008, 612, 152-159.

(14) Molins-Delgado, D.; Távora, J.; Silvia Díaz-Cruz, M.; Barceló, D. UV filters and benzotriazoles in urban aquatic ecosystems: The footprint of daily use products. Sci. Total Environ. 2017, 601-602, 975-986.

(15) Cabrera-Peralta, J.; Peña-Alvarez, A. Simple method for the determination of personal care product ingredients in lettuce by ultrasound-assisted extraction combined with solid-phase microextraction followed by GC-MS. J. Sep. Sci. 2018, 41 (10), 2253-2260.

(16) Gago-Ferrero, P.; Alonso, M. B.; Bertozzi, C. P.; Marigo, J.; Barbosa, L.; Cremer, M.; Secchi, E. R.; Azevedo, A.; Lailson-Brito Jr., J.; Torres, J. P. M.; Malm, O.; Eljarrat, E.; Díaz-Cruz, M. S.; Barceló, D. First determination of UV filters in marine mammals. Octocrylene levels in Franciscana dolphins. Environ. Sci. Technol. 2013, 47, 5619-5625.
(17) Balmer, M. E.; Buser, H.-R.; Müller, M. D.; Poiger, T. Occurrence of some organic UV filters in wastewater, in surface waters, and in fish from Swiss lakes. Environ. Sci. Technol. 2005, 39, 953-962.

(18) Buser, H.-R.; Balmer, M. E.; Schmid, P.; Kohler, M. Occurrence of UV filters 4-methylbenzylidene camphor and octocrylene in fish from various Swiss rivers with inputs from wastewater treatment plants. Environ. Sci. Technol. 2006, 40, 1427-1431.

(19) Blüthgen, N.; Meili, N.; Chew, G.; Odermatt, A.; Fent, K. Accumulation and effects of the UV-filter octocrylene in adult and embryonic zebrafish (Danio rerio). Sci. Total Environ. 2014, 476477, 207-217.

(20) Gago-Ferrero, P.; Díaz-Cruz, M. S.; Barceló, D. Multi-residue method for trace level determination of UV filters in fish based on pressurized liquid extraction and liquid chromatography-quadrupolelinear ion trap-mass spectrometry. J. Chromatogr. A 2013, 1286, 93101.

(21) Bachelot, M.; Li, Z.; Munaron, D.; Le Gall, P.; Casellas, C.; Fenet, H.; Gomez, E. Organic UV filter concentrations in marine mussels from French coastal regions. Sci. Total Environ. 2012, 420 273-279.

(22) Molins-Delgado, D.; Muñoz, R.; Nogueira, S.; Alonso, M. B.; Torres, J. P.; Malm, O.; Ziolli, R. L.; Hauser-Davis, R. A.; Eljarrat, E.; Barceló, D.; Díaz-Cruz, M. S. Occurrence of organic UV filters and metabolites in lebranche mullet (Mugil liza) from Brazil. Sci. Total Environ. 2018, 618, 451-459.

(23) Tsui, M. M. P.; Lam, J. C. W.; Ng, T. Y. Y.; Ang, P. O.; Murphy, M. B.; Lam, P. K. S. Occurrence, distribution, and fate of organic UV filters in coral communities. Environ. Sci. Technol. 2017, $51,4182-4190$.

(24) Bury, D.; Belov, V. N.; Qi, Y.; Hayen, H.; Volmer, D. A.; Brüning, T.; Koch, H. M. Determination of urinary metabolites of the emerging UV filter octocrylene by online-SPE-LC-MS/MS. Anal. Chem. 2018, 90, 944-951.

(25) Thompson Legault, J.; Strittmatter, L.; Tardif, J.; Sharma, R.; Tremblay-Vaillancourt, V.; Aubut, C.; Boucher, G.; Clish, C. B.; Cyr, D.; Daneault, C.; Waters, P. J.; Laprise, C.; Rioux, J. D.; Mootha, V. K.; Des Rosiers, C. A metabolic signature of mitochondrial dysfunction revealed through a monogenic form of Leigh syndrome. Cell Rep. 2015, 13, 981-989.

(26) Frye, R. E.; Melnyk, S.; Macfabe, D. F. Unique acyl-carnitine profiles are potential biomarkers for acquired mitochondrial disease in autism spectrum disorder. Transl. Psychiatry 2013, 3, e220.

(27) Thomas, R. H.; Foley, K. A.; Mepham, J. R.; Tichenoff, L. J.; Possmayer, F.; MacFabe, D. F. Altered brain phospholipid and acylcarnitine profiles in propionic acid infused rodents: further development of a potential model of autism spectrum disorders. $J$. Neurochem. 2010, 113, 515-529.

(28) Mihalik, S. J.; Goodpaster, B. H.; Kelley, D. E.; Chace, D. H.; Vockley, J.; Toledo, F. G. S.; DeLany, J. P. Increased levels of plasma acylcarnitines in obesity and type 2 diabetes and identification of a marker of glucolipotoxicity. Obesity 2010, 18, 1695-1700. 
FOR TOC ONLY

Octocrylene uncovered

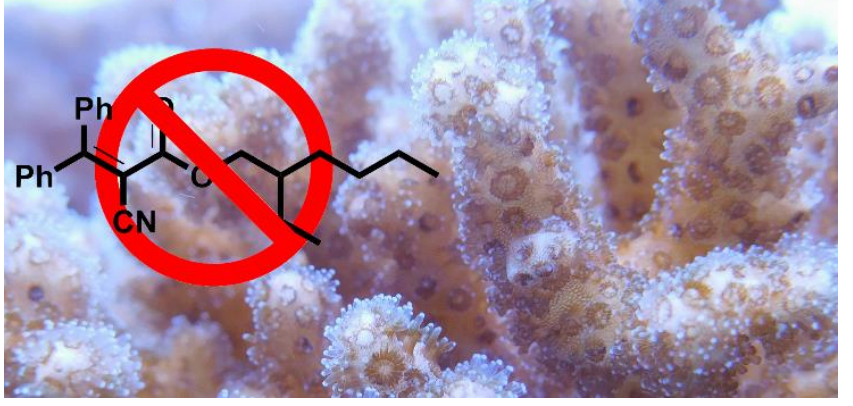

